\title{
Sustainability in complex environments: Making sense of the Katrina lawsuits
}

\author{
Catalin Ratiu ${ }^{1}$ and Beverlee B. Anderson ${ }^{2}$ \\ California State University San Marcos, USA
}

\begin{abstract}
Purpose - The meaning of sustainability continues to be debated by scholars and professionals alike. But how do individuals, who are expected to contribute to implementing sustainability actions, perceive this important concept? The purpose of this paper is to explore how individuals relate to the multidimensionality of sustainability.

Design/methodology/approach - We use a qualitative design to learn how individuals understand and prioritise the various dimensions of sustainability. Respondents were asked to react in essay form to a narrative that weaves social, environmental, economic and legal issues, and offer a recommended course of action.

Research limitations - The research is limited by the convenience sample used, which may offer a skewed distribution.

Findings - The findings are mixed, showing that sustainability is yet to mature as a concept in the minds of the general public. Encouragingly, we find evidence that most respondents are aware of the primary dimensions of sustainability.

Originality - The study uses an innovative methodology to learn how individuals perceive a very complex topic.

Implications - While defining sustainability conceptually continues to preoccupy scholars and policymakers, educating the general public on these advancements should also be prioritised, given the high reliance on individuals to implement the many sustainability initiatives and innovations in existence.
\end{abstract}

Keywords - Sustainability, Sustainable development

Paper type - Research paper

\footnotetext{
${ }^{1}$ Catalin Ratiu, PhD, Assistant Professor of Management, California State University San Marcos, USA, Email: cratiu@csusm.edu

${ }^{2}$ Beverlee B. Anderson, PhD, Professor of Business and Marketing, California State University San Marcos, USA, Email: banderso@csusm.edu
} 


\section{Introduction}

The meanings of sustainability and sustainable development continue to be debated by scholars and professionals alike. There continues to be increased interest in the topic, yet we are not any closer to a unifying definition.

In a recent paper, Ratiu and Anderson (2013) survey how academics, governments, trade professionals and the general public view sustainable development and show that, while most of these actors set priorities around various salient dimensions, there is little convergence around how to formulate and implement strategies in this area. Furthermore, despite decades of interest, they show that the general public is yet to be fully educated on the triple bottom-line dimensions of sustainability.

We build on prior work in the area of sustainable development dimensions and ask how do individuals, who are expected to contribute to implementing sustainability actions, perceive this important concept? Furthermore, are individuals able to stay focused on the triple bottom-line when confronted with a complex choice that includes other important dimensions, such as the legal environment? Existing studies have previously looked at how the general public can view sustainability conceptually, but we know of no study that explores how individuals apply sustainability dimensions to the often-convoluted issues that continue to develop in the world.

The purpose of this paper is to explore how individuals relate to the multidimensionality of sustainability given a complex situation whose triple bottom-line implications are not obvious. We do this through a qualitative design, which asked respondents to react to a brief case involving issues pertaining to the economy, the environment and society, in the context of a legal battle. Through this manipulation we explore the role of the legal environment in either enhancing or diminishing an individual's perspective on sustainable development.

\section{Conceptual context}

We agree with established definitions of sustainability that link the triple bottom-line with resource dependence in a forward-looking context. We further consider sustainability to be an integrative concept that allows multiple disciplines to contribute new findings or draw knowledge into an ever-evolving awareness of the impact of human activity on the earth's fundamental systems. Within this broad context, our understanding of what sustainability means can evolve, be fluid, or, at times, become at odds with how other actors conceptualise or implement strategies meant to answer some of the same global questions. As a result, we may acknowledge that while the major definitions of sustainability agree upon a set of approachable dimensions, such as the triple bottomline, the applicable realms of organisational activities are subject to interpretation, which results in a multitude of definitions, meanings and implementations.

In a recent piece, Morelli (2013) shows how the notion of sustainable development was transferred from the domain of sciences, to a popular concept, interpretable by anyone. Other authors suggest that the overuse of sustainability and sustainable development has led to their abuse by most actors involved in formulating actionable strategies or the general public, tasked to convert their understanding of these important notions into day-to-day efforts (Károly, 2013). The involvement of the general public in the area of interpretation of an often ill-understood concept has led to major national and international debates, which Hoffman (2010) has shown are cultural in nature, and retain very little of their scientific basis. 
To reconcile this issue, we argue that it is imperative to bring focus and agreement around the core dimensions of sustainable development. Furthermore, we need to understand the primary motivation and guiding mechanisms of the organisations that have the capacity to change how sustainable development is perceived, implemented and prioritised. These entities include business organisations, government and nongovernmental actors, as well as the collaborative agreements developed among them, at the national and international levels. Moreover, there is a continuous need to train and educate the general public, so that their role is understood. Towards that end, in this paper, we focus on individual understanding of these complex issues by showing how the general public reacts and makes sense of them, even when their complexity may be masked by legal or economic contexts.

\section{Methods}

\section{Design}

We use a qualitative design to learn how individuals understand and prioritise the various dimensions of sustainability. Respondents were asked to react in essay form to a narrative that weaves social, environmental, economic and legal issues and to offer a recommended course of action. By being asked to offer a recommended course of action, respondents had to develop a clear position, favouring one stakeholder or a group of similar actors involved in this debate. Also, the legal context simulates the complexity of a real-life situation, where the dimensions of the triple bottom-line, or any accepted definitions of sustainable development are rarely as clear and explicit as they appear in theory.

\section{Context}

The research was conducted in the context of a legal debate involving real-life lawsuits filed by more than 500,000 citizens affected by the Katrina hurricane in Louisiana. Appendix 1 shows the details of the case shown to respondents. Specifically, the case involves four stakeholder groups: the plaintiffs who filed the suit as individuals affected by the poor levy maintenance, the federal government of the United States called for levee failures and flooding, the US Army Corps of Engineers liable for lax maintenance of the shipping channel, and a contractor. For the purpose of this research, we placed the stakeholders in two categories: plaintiffs and the government. Furthermore, the case presented contains information that fits elements of the triple bottom-line, including issues relating to economic, environment and social spheres.

\section{Data}

were collected from a convenience sample of 36 students taking a senior level course in business administration at a US school. The survey instrument shown in Appendix 1 was used to solicit position papers from the respondents, which were submitted via email. The final sample consists of about 50 pages of text.

\section{Measures}

To examine how the general public reacts to this legal conundrum involving sustainable development dimensions in action, we measured which stakeholder group they would have favoured, given the opportunity to make the same legal decision. We coded Favours plaintiffs, if the respondent was in favour of the case filed by the more than 500,000 people affected by the hurricane. If respondents were in agreement with the decision as presented in the article, we coded 
Favours dismissal. Further, we coded for two other sets of measures, depending on how respondents justified their position. Specifically, we looked at how responsibility was assigned and what was the primary logic to build the justification. For both of these categories, we distinguished between economic, environmental, social and legal logics.

\section{Analytical procedures}

We adopted an inductive approach to identify theoretical constructs that could inform theoretical development (Glaser and Strauss, 1967). This approach involved a multi-stage content analysis technique (Miles and Huberman, 1994). Using HyperResearch software, sections of text from each data source were coded. The first coding stage included the identification of elements that pertain to triple bottom-line. As it became apparent that justifications were made at different levels, the second coding involved distinguishing between instances where respondents assigned responsibility from instances where they built an argument. For these categories, we focused on codes involving economic, environmental, social and legal logics.

\section{Results}

Overall, we find that there is an almost even split between respondents who favour the plaintiffs $(47 \%)$ versus those who favour the dismissal of the case (53\%). Quantitative results from the content analysis are shown in Table 1. While we expected that there would not be a clear-cut winner in the debate, the nearly equal division of opinions was surprising. Still, the small-margin majority acquiesced with the decision as made, to dismiss the trial and not hold the government, US Marine Corps, or contractor responsible for the maintenance of the levees.

Table 1. Results from content analysis

\begin{tabular}{|c|c|c|c|c|}
\hline & $\begin{array}{l}\text { Favours } \\
\text { plaintiffs }\end{array}$ & $\%$ & $\begin{array}{l}\text { Favours } \\
\text { dismissal }\end{array}$ & $\%$ \\
\hline Count & 17 & 47 & 19 & 53 \\
\hline Argument contains economic logic & 7 & 41 & 8 & 42 \\
\hline Argument contains environmental logic & 6 & 35 & 11 & 58 \\
\hline Argument contains legal logic & 17 & 100 & 15 & 79 \\
\hline Argument contains a social logic & 11 & 65 & 3 & 16 \\
\hline $\begin{array}{l}\text { Uses economic logic to assign responsibility } \\
\text { Uses environmental logic to assign }\end{array}$ & 2 & 12 & 2 & 12 \\
\hline responsibility & 1 & 6 & 14 & 74 \\
\hline Uses legal logic to assign responsibility & 16 & 94 & 5 & 26 \\
\hline Uses social logic to assign responsibility & 3 & 18 & 1 & 5 \\
\hline
\end{tabular}




\section{Justification}

When looking at the responses in favour of the plaintiffs, several observations should be made. First, note in the grouping of codes relative to the logic of the argument or justification that all those in favour of the plaintiffs use a primary legal justification. While they recognise that triple bottom-line considerations are also important, a social logic is acknowledged by $65 \%$, while the other pillars (economic and environmental) are represented at less than 50\% each. Overwhelmingly, the respondents in favour of the plaintiffs believed that the primary justification of their position was a legal one, based on the fact that the plaintiffs had little recourse to the hurricane's consequences, that the government had a legally binding duty to maintain the levees and that this fell under the administrative duties of its subcontractors and agencies, such as the US corps.

The arguments in favour of dismissing the case were spread out more, with a large majority (79\%) basing their justifications on a legal argument. To illustrate, one of the respondents noted that,

"Force majeure states that the defendant could not have predicted the hurricane and its damages and can therefore not be held accountable for the consequences."

An environmental logic was used to justify the dismissal by $58 \%$ of these respondents, who considered the event unavoidable and beyond the control of any actor, including the government. One of the respondents states this when saying,

"I would have to say that by living there they should know better. They are under sea level and this has happened many times in the past when hurricanes have come through and before levees were even built."

Furthermore, almost half of the respondents believed that the case had some economic underpinnings $(42 \%)$. This view is represented by one of the respondents, who explained,

"The residents, businesses, and governments received some type of economic benefit from the canal and willingly resided or operated in proximity to it."

Looking across the figures among those in favour of the plaintiffs versus those in favour of the dismissal, we noted many similarities. But note a significant discrepancy. Of those in favour of the plaintiffs, $65 \%$ used a social justification, while only $16 \%$ did so of those in favour of dismissing the case. In other words, when arguing for the plaintiffs, a social justification was the second most important logic in building the argument, but not nearly as important for those in favour of the government.

\section{Responsibility}

When assigning responsibility, the results are far less equivocal. Those in favour of the plaintiffs used a legal logic to assign responsibility by a large margin (94\%), while those in favour of the government chose an environmental logic to assign responsibility, by a significant degree (74\%). 
The legal logic when assigning responsibility is justified by the notion that a tacit or explicit agreement was broken when the government, through its agents, failed to adequately maintain the levees, which lead to significant property damages. One of the respondents notes that,

"However a ruling was made that completely insulated the government from liability, which would make it extremely difficult for the government to pay damages in the future. This is not okay. Lax maintenance of the shipping canal and excavation work that weakened the walls caused the flooding. The US corps also failed to properly maintain a channel, which allowed protective marshland to wash away. The evidence is there that the US corps were responsible for the flooding. Therefore I do not understand why the government should be exempt from liability. It simply doesn't make sense from a legal point of view as to why the government was given a free pass."

Some in favour of the plaintiffs also invoked a social logic to assign responsibility, by arguing that the government should have been more in tune with the social needs of the region and their social responsibility. For instance, one of the respondents explained that,

"They were responsible for keeping the general public safe by preventing as much disaster as possible. However, they broke this responsibility and should therefore suffer the consequences of their actions."

At the same time, those in favour of dismissing the case focused primarily on assigning responsibility using an environmental logic. The core of the argument aligned around the idea that the government and its agencies cannot be held responsible for acts of God. A typical argument in this category is illustrated by the following respondent, who said,

"Therefore, those flood walls failed because the hurricane was simply too powerful for those walls to hold."

Others assigned responsibility based on a more complex argument building, grounded in economic, social, environmental and legal logic all at the same time. This is illustrated in the following response,

"Residents, businesses, and governments benefitted in some way by selecting to reside or operate in the area/environment which was in proximity to the shipping. Whether they benefitted from lower property/housing costs or benefitted from operational costs or benefitted financially/economically they knew the risks and were willing to take the risk to accumulate reward. They could have selected an area with less potential for harm, which possibly might have carried the potential for less reward, but for whatever reason they selected to reside and/or operate in the vicinity of the New Orleans's Industrial Canal."

To conclude, respondents vary in their assignment of responsibility and argument building logic depending on which side they favour. Moreover, those in favour of the people seem to be more definitely, as evidenced by high percentages around key dimensions (100\% and 94\% for legal). The same level of agreement is not to be found among the respondents in favour of dismissing the case. Note also that, while the assignment of responsibility tends to focus on a primary logic, the 
justification is more widespread and respondents use almost all the different logics in their arguments.

\section{Discussion and conclusion}

Overall, the findings are mixed, showing that sustainability is yet to mature as a concept in the minds of the general public. Encouragingly, we find evidence that most respondents are aware of the primary dimensions of sustainability and use them to build their arguments in this case. Nevertheless, their understanding of these dimensions is distinct, depending on which side they choose. For instance, environmental arguments, although used by both sides, do not have the same thrust, as respondents adapt the dimension to suit their argument. This is perhaps one of the most important findings of this work, as it shows how easy it is to manipulate the founding and most agreed upon dimensions of sustainability, to suit the needs of the desired rhetoric.

A further point worth noting regards the role of the legal environment in promoting sustainable development. In this case, regulatory agencies representing the US government were cautious in responding to the claims made by the local citizens in the aftermath of a natural disaster. It is well known that legal protection is necessary for conservation efforts. Therefore this study sheds light on the potential of the government but also its limitations in effectively promoting sustainable development.

We contribute to the literature on sustainable development in a number of ways. First, we show that the general public is quite knowledgeable of the core dimensions of the triple bottom-line. Second, we also show that, when complexity is introduced, the general public is divided on what sustainability means and how it is to be used. This is important because it highlights the importance of further defining sustainability measures, and enhancing education on the core dimensions. Third, the study uses an innovative methodology to learn how individuals perceive a very complex topic. By introducing the legal variable into the mix, we can explore how individuals react and apply these concepts in an experimental context.

We conclude that, while defining sustainability conceptually continues to preoccupy scholars and policymakers, educating the general public on these advancements should also be prioritised, given the high reliance on individuals to implement the many sustainability initiatives and innovations in existence. 


\section{References}

Glaser, B.G. and Strauss, A.L. (1967), The Discovery of Grounded Theory: Strategies for Qualitative Research, Chicago, Aldine Publishing Company.

Hoffman, A.J. (2010), "Climate change as a cultural and behavioral issue: Addressing barriers and implementing solutions", Organizational Dynamics, Vol. 39 No. 4, pp. 295-305.

Károly, K. (2013), "Rise and fall of the concept sustainability", Journal of Environmental Sustainability, Vol. 1 No. 1, pp. 1-12.

Miles, M.B. and Huberman, A.M. (1994), Qualitative Data Analysis: An Expanded Sourcebook. Sage.

Morelli, J. (2013), "Environmental sustainability: A definition for environmental professionals", Journal of Environmental Sustainability, Vol. 1 No. 1, pp. 1-9.

Ratiu, C. and Anderson, B. (2013), The Identity Crisis of Sustainable Development, World Association for Sustainable Development, London, UK. 


\section{Appendix 1 \\ Survey instrument used to collect data}

Complete the following assignment individually and in writing without conducting any additional research (e.g., internet search, group discussions, interviews). This assignment is being graded based on a pass/fail protocol, not on the amount of knowledge or quality of analysis you display.

The following news article appeared in a recent issue of the Wall Street Journal. Read it carefully:

\section{Louisiana. Katrina Suits against US Dismissed by Judge}

Dozens of lawsuits seeking damages from the federal government for Hurricane Katrina-related levee failures and flooding in New Orleans have been dismissed. The move by US District Judge Stanwood Duval Jr. came more than a year after a federal appeals court overturned his ruling that held the US Army Corps of Engineers liable for flooding after the 2005 hurricane, caused by lax maintenance of a shipping channel. Judge Duval has also dismissed a parallel lawsuit against a contractor. That suit claimed excavation work weakened floodwalls in New Orleans's Industrial Canal. Judge Duval entered the orders to dismiss the cases on Dec. 20.

More than 500,000 residents, businesses and governments had filed claims against the corps. Judge Duval had ruled in 2009 that the corps was liable for the flooding of certain neighborhoods because it failed to properly maintain a channel, allowing protective marshland to wash away. The Fifth Circuit Court of Appeals initially agreed with that decision. But in September, a three-judge panel reversed its earlier opinion, saying the new ruling "completely insulates the government from liability". The ruling could make it extremely difficult to force the government to pay damages for future mishaps. Under federal law, the government can't be sued over actions based "on considerations of public policy", the appeals panel wrote. The corps' decisions regarding the shipping channel fall under that protection, the judges wrote.

- Associated Press

Consider the issues presented in this article.

How would you have ruled in this lawsuit?

Write a short essay of at least 3-paragraphs but not more than 2 single-spaced pages in which you:

- $\quad$ develop a clear position

- $\quad$ justify your position based on the core arguments

- $\quad$ explain why other possible views are less justifiable in the context

\section{About the authors}

Dr. Catalin Ratiu is assistant professor of strategic management at California State University, San Marcos. He earned a $\mathrm{PhD}$ in strategic management from Concordia University in Montréal and has previously held academic appointments at the universities Concordia and McGill in the areas of strategy, corporate sustainability and international business.

Prof. Beverlee B. Anderson received her $\mathrm{PhD}$ in Marketing from The Ohio State University. She currently serves as Professor of Business and Marketing at California State University, San Marcos. She 
has held a variety of teaching and administrative positions at Universities in the United States. She is past President of Marketing Educators Association and has taught in graduate programmes in Mexico and India. 